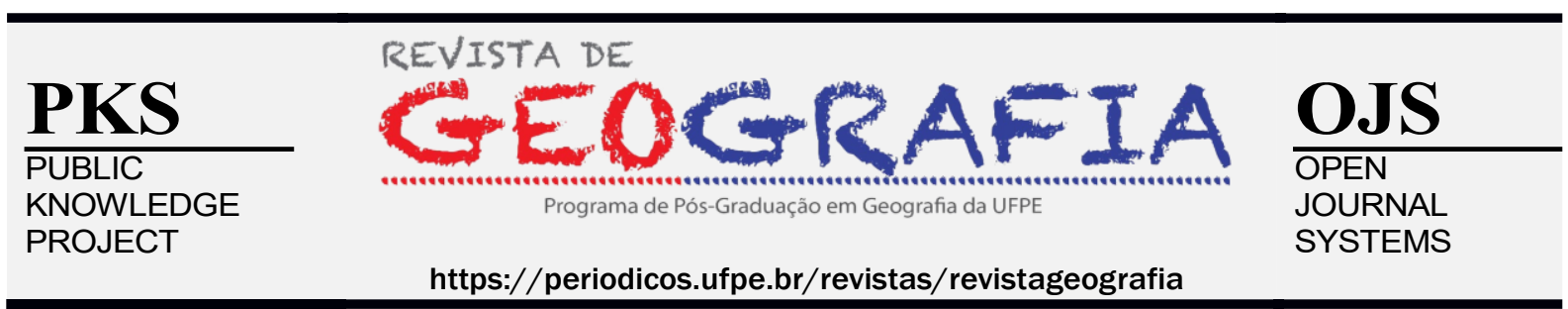

\title{
CONTRIBUIÇÕES DA CIÊNCIA GEOGRÁFICAAOS ESTUDOS AGRÁRIOS: UMA ANÁLISE DA REVISTA BRASILEIRA DE GEOGRAFIA E DO BOLETIM GEOGRÁFICO
}

\author{
João Emerson Cunha Silva ${ }^{1}$, Aline Barboza de Lima ${ }^{2}$
}

\begin{abstract}
${ }^{1}$ Universidade Federal de Campina Grande, Graduando em Geografia pela Universidade Federal de Campina Grande, Campina Grande - PB, E-mail:jemersonsantosc@gmail.com; https://orcid.org/0000-0002-7797-6939.

${ }^{2}$ Universidade Federal de Campina Grande, Dra. em Geografia Humana pela Universidade de São Paulo, professora da Universidade Federal da Paraíba - João Pessoa -PB, E-mail:alinelima.ufcg@gmail.com; https://orcid.org/0000-0002-6795-6264.
\end{abstract}

Artigo recebido em 21/07/2021 e aceito em 18/09/2021

\begin{abstract}
RESUMO
O Boletim Geográfico e a Revista Brasileira de Geografia (RBG) são dois importantes periódicos surgidos no século XX, período em que a geografia iniciou seu processo de institucionalização no Brasil, tendo grande importância no âmbito da produção de conhecimentos geográficos. O objetivo geral do trabalho é compreender os principais conceitos e teorias presentes nos artigos de geografia agrária publicados no Boletim Geográfico e na RBG. O método utilizado foi a revisão bibliográfica dos artigos referentes a geografia agrária e áreas afins dos dois periódicos supracitados. Nesse contexto, verificouse que diferentes correntes do pensamento geográfico estiveram presentes nas publicações analisadas, em cada uma delas predominando conceitos, teorias e temáticas específicos. Ademais, constatou-se que os artigos presentes no conjunto dos dois periódicos apresentaram predominância de conceitos e temáticas distintos. Assim, compreendeu-se que em ambos os periódicos a reflexão de temáticas referentes à geografia agrária, por diversos autores, englobaram diferentes referenciais teóricos e metodológicos na análise de questões ligadas ao mundo agrário brasileiro.
\end{abstract}

Palavras-chave: Geografia Agrária; Teorias; Epistemologia.

\section{CONTRIBUTIONS OF GEOGRAPHICAL SCIENCE TO AGRICULTURAL STUDIES: AN ANALYSIS OF "REVISTA BRASILEIRA DE GEOGRAFIA" AND THE" BOLETIM GEOGRÁFICO”}

\begin{abstract}
The "Boletim Geográfico" and the "Revista Brasileira de Geografia" (RBG) are two important journals that emerged in the twentieth century, when geography began its process of institutionalization in Brazil, having great importance in the production of geographic knowledge. This research investigated concepts and theories present in the agrarian geography articles published in these journals. The method used was the bibliographical review of the articles referring to agrarian geography and related areas. In this context,
\end{abstract}


the study found different currents of geographic present in the publications analyzed, in each of them predominating specific concepts, theories and themes. In addition, magazines have predominant concepts that are distinct from each other. Finally, we understand that, in both journals, the reflection of themes related to agricultural geography includes different theoretical and methodological references in the analysis of Brazilian agriculture, that connect to political, economic and social contexts over time.

Keywords: Agrarian Geography. Theories. Epistemology.

\section{CONTRIBUCIONES DE LAS CIENCIAS GEOGRÁFICAS A LOS ESTUDIOS AGRÍCOLAS: ANÁLISIS DE LA REVISTA BRASILEIRA DE GEOGRAFIA Y EL BOLETIM GEOGRÁFICO}

\section{RESUMEN}

El Boletim Geográfico y la Revista Brasileira de Geografia (RBG) son dos importantes publicaciones periódicas que surgieron en el siglo $\mathrm{XX}$, período en el que la geografía inició su proceso de institucionalización en Brasil, teniendo gran importancia en la producción de conocimiento geográfico. El objetivo general del trabajo es comprender los principales conceptos y teorías presentes en los artículos de geografía agraria publicados en el Boletim Geográfico y en la RBG. El método utilizado fue la revisión bibliográfica de artículos referidos a la geografia agraria y áreas afines de las dos revistas mencionadas. En este contexto, se encontró que diferentes corrientes de pensamiento geográfico estaban presentes en las publicaciones analizadas, en cada una de ellas predominando conceptos, teorías y temas específicos. Además, se encontró que los artículos presentes en el conjunto de dos revistas presentaron un predominio de conceptos y temas distintos. Así, se entendió que en ambas publicaciones periódicas la reflexión de temas relacionados con la geografía agraria, de varios autores, abarcó diferentes referentes teóricos y metodológicos en el análisis de temas relacionados con el mundo agrario brasileño.

Palabras clave: Geografía Agraria. Teorías. Epistemología.

\section{INTRODUÇÃO}

O presente trabalho trata-se de uma revisão bibliográfica que objetivou compreender os principais conceitos e teorias recorrentes na história do pensamento geográfico da Geografia Agrária brasileira, através da análise de produção científica publicada em dois periódicos: a Revista Brasileira de Geografia (RBG) e o Boletim Geográfico.

Os objetivos específicos foram sistematizar a produção bibliográfica sobre Geografia Agrária entre os anos de 1930 e $2006^{1}$, analisar as principais correntes de pensamento e conceitos utilizados nos estudos geográficos sobre o campo brasileiro, bem como identificar predominância de abordagens no conjunto da revisão bibliográfica pesquisada (RBG e Boletim Geográfico).

A RBG surgiu no ano de 1939, período em que a geografia Brasileira estava se institucionalizando, assim, tendo grande importância nesse processo, haja vista que diversas

\footnotetext{
${ }^{1}$ O recorte temporal utilizado levou em consideração o período de edição das revistas. O período de edição do Boletim Geográfico ocorreu entre 1943 e 1978 e da Revista Brasileira de Geografia ocorreu entre 1939 e 2006 , com a edição de mais um volume em 2008.
} 
temáticas geográficas brasileiras começaram a ser abordadas a partir das publicações desse periódico. Concomitantemente, o Boletim Geográfico, surgido em 1943, desenvolveu uma importância análoga à da RBG, onde as publicações versaram acerca de questões geográficas, corroborando para a construção da geografia brasileira.

Nesta perspectiva, tanto a RBG quanto o Boletim Geográfico tiveram influência na construção da Geografia Brasileira, consequentemente, também da Geografia Agrária no Brasil. Os referenciais teóricos analisados revelaram contextos sociais, científicos e culturais de cada período.

Nesse sentido, engloba-se outra importante questão que será desenvolvida no transcorrer do trabalho, a identificação de teorias que influenciaram no pensamento e na forma de compreender as questões referentes ao mundo agrário brasileiro, assim, estabelecendo-se uma relação direta entre a História do pensamento geográfico e suas correlações com os trabalhos desenvolvidos em Geografia Agrária, tanto na Revista Brasileira de Geografia, quanto no Boletim Geográfico.

\section{METODOLOGIA}

A metodologia utilizada teve como base a revisão bibliográfica efetuada tanto na Revista Brasileira de Geografia quanto no Boletim geográfico. Inicialmente, foi realizado um levantamento bibliográfico nessas revistas, com o intuito de encontrar os artigos dos dois periódicos que discutissem temáticas referentes à Geografia Agrária e também a outras áreas do conhecimento que estão relacionadas a mesma, como a Sociologia Rural, Agronomia, Geografia econômica e a Nutrição.

Após esse processo inicial de identificação, foi realizada a seleção dos artigos das áreas afins e dos autores da Geografia Agrária para a leitura e posterior levantamento de dados e

resultados através da análise dos mesmos. Nesse sentido, as análises e posteriores identificações de conceitos, teorias, temas e metodologias predominantes nos artigos foram realizadas através do levantamento e posterior revisão bibliográfica.

No Boletim Geográfico foram catalogados 72 artigos com temáticas referentes a Geografia Agrária ou que abordaram temáticas em áreas afins, como a Agronomia, Nutrição, e Geografia Econômica. Nesse conjunto, foram selecionados e consultados 36 artigos para o desenvolvimento da pesquisa. Em relação à Revista Brasileira de Geografia foram catalogados 94 artigos referentes a temáticas da Geografia Agrária e áreas afins. Sendo que nesse conjunto, foram selecionados 47 artigos para a pesquisa. Os artigos foram selecionados de forma 
qualitativa, priorizando-se aqueles cujo conteúdo principal referia-se aos estudos agrários e os pesquisadores possuíam efetiva colaboração para os estudos da Geografia Agrária.

\section{RESULTADOS E DISCUSSÃO}

\section{Geografia Agrária Clássica na Revista Brasileira de Geografia e no Boletim Geográfico}

Nas décadas de 1930 e 1940 têm início o processo de institucionalização da Geografia como ciência no Brasil, através não apenas da criação de cátedras em universidades brasileiras, como na Universidade do Distrito Federal, mas também por meio de dois periódicos do Instituto Brasileiro de Geografia e Estatística (IBGE): o Boletim Geográfico e a RBG.

Nos primeiros artigos relacionados à Geografia Agrária analisados no Boletim Geográfico, verificou-se a predominância da Geografia Clássica ${ }^{2}$, sob forte influência de autores como Vidal de La Blache e Friedrich Ratzel. O historicismo e o positivismo foram as correntes filosóficas que predominaram nessas publicações.

No âmbito do historicismo, os autores franceses que vieram ao Brasil, como Pierre Monbeig e Pierre Deffontaines (1953) que apresentaram em seus trabalhos aspectos ligados ao historicismo na investigação de questões acerca do mundo agrário, como a descrição dos aspectos físicos da área estudada, seguida da descrição do gênero de vida das áreas pesquisadas. Nesse contexto, os trabalhos de Monbeig tratam de questões relacionadas às ruralidades através do viés historicista, destacando, em especial, questões relacionadas à estrutura agrária e às paisagens.

A ênfase em estudos da Geografia Agrária nos gêneros de vida evidencia a influência do possibilismo lablacheano, característico da Escola Francesa em autores como Deffontaines e outros mais, como Nilo Bernardes (1963), que trabalhou em alguns artigos questões referentes aos gêneros de vida rurais no Brasil e aos habitats rurais, a partir da descrição da paisagem, em sua dimensão física e cultural.

Assim, entre outras características, o historicismo da Geografia Agrária Clássica é marcado também pela descrição minuciosa das áreas estudadas, tanto no âmbito do modo como as populações interagiam com o meio natural na qual estavam inseridas, quanto na descrição

\footnotetext{
${ }^{2}$ Utilizamos o termo "clássica" conforme discutido por Andrade (2006), compreendendo que "Torna-se difícil estabelecer os limites de cada período, uma vez que as transformações e as mudanças na orientação do estudo e do ensino de Geografia se processam lentamente e em uma mesma fase há autores que se encontram em um e em outro período, da mesma forma que um mesmo autor participa, através dos seus trabalhos, de dois períodos que se sucedem" (ANDRADE, 2006, p.99).
} 
de aspectos físicos, históricos e sociais das áreas estudadas, em que destacavam-se temas como paisagem rural, estrutura agrária, região, proletariado rural e paisagem cultural.

Na década de 1960, o historicismo continua a ser trabalhado por outros autores, todavia publicações de Orlando Valverde e Manuel Correia de Andrade, que são precursores da Geografia Crítica, passam a analisar as questões da realidade agrária em tons mais críticos. Vale salientar que a produção de Valverde esteve mais presente na RBG, onde o mesmo publicou 5 dissertações que versavam sobre diversas temáticas, entre as quais: imigração, gêneros de vida, agricultura brasileira e a relação entre geografia agrária e geografia econômica. Ademais, também vale destacar que outros autores vão publicar artigos na RBG com predominância do historicismo, entre os quais podemos destacar Côrrea (1963).

Além destas vertentes teóricas ligadas à Geografia regional francesa, também estiveram presentes ao longo da história da RBG e do Boletim Geográfico outras correntes de pensamento e visão de mundo na Geografia, entre elas, o positivismo, a qual foi muito influente em parte das publicações ligadas à Geografia Clássica e em outras escolas que se sucederam na História do pensamento geográfico, como na Geografia Teorético-Quantitativa.

No Boletim Geográfico, os artigos, textos e dissertações com influências do positivismo predominaram até os anos 1950, onde eram trabalhadas questões agrárias com certa influência do determinismo geográfico e do darwinismo social, entre outros caracteres que marcaram as diretrizes estabelecidas pelo positivismo na forma de conceber e produzir ciência.

Entre os autores que produziram alguns trabalhos nesta perspectiva, está Mario Lacerda de Mello (1948), o qual apresenta em seu artigo, especificamente nas considerações econômicas da cultura do açúcar, uma visão determinista acerca de questões relacionadas à localização das áreas de cultivo dessa cultura. Abaixo, segue um breve trecho que ilustra o determinismo geográfico na obra de Melo (1948):

[...] torna-se forçosa concluir que quanto mais acentuada fôr a tendência monocultora de uma população tanto mais imperativamente se lhe impõe a necessidade de fazer comércio. E' mais um elemento a esclarecer a localização das áreas canavieiras em regiões geogràficamente predestinadas a um comércio ativo. (MELO, 1948, p. 689)

Assim, a ideia da predestinação evidente no trecho marca a presença do determinismo geográfico no artigo analisado. Além disso, outros autores também publicaram artigos com afinidades teórico-metodológicas com a corrente positivista, como Castro (1948), onde em seus estudos acerca das áreas alimentares do Brasil, o autor apresenta o racionalismo e o método 
característicos do positivismo. Silva e Nunes (2017), acerca dessa fase dos estudos de Castro relatam:

\begin{abstract}
Assim, podemos notar que essa é a fase em que os estudos de Castro apresentam um franco diálogo com o positivismo, concentrando-se no método mais fisiológico, a partir da distinção entre o normal (população bem alimentada) e o patológico (doenças carenciais), com a finalidade de agir sobre este último com ações racionais na tentativa de constituição de uma educação alimentar, para que o Brasil alcançasse uma dieta alimentar que pudesse modernizar o país e curar a patologia da fome. (SILVA; NUNES, 2017, p.3682)
\end{abstract}

Já na Revista Brasileira de Geografia, o positivismo esteve ligado principalmente em aplicações da Teoria do Estado Isolado de Von Thünen à realidade agrária brasileira, onde através desse modelo, se estabeleceriam no Brasil estudos sobre os anéis agrários influenciados pela distância aos mercados.

Destacam-se inclusive, trabalhos metodológicos que investigam os prós e contras da Teoria de Von Thünen, como o fez Mesquita (1978). Waibel (1948) também realizou uma série de trabalhos relacionados a aplicação da teoria de Von Thünen à realidade agrária brasileira, conseguindo importantes resultados que vão influenciar outros teóricos a trabalharem com esta metodologia de estudo das questões agrárias. Em um de seus trabalhos, Waibel destaca questões teórico-metodológicas do modelo de Von Thünen, ressaltando seu surgimento e considerações pormenorizadas acerca do funcionamento do modelo, incluindo até mesmo sua aplicação. Contudo, é importante destacamos que as análises teóricas de Waibel fizeram parte da oposição à escola determinista e à reafirmação da cientificidade das ciências humanas.

Desse modo, as principais características metodológicas e teóricas executadas em trabalhos na Geografia Agrária Clássica giraram em torno da descrição das realidades estudadas. Assim, conforme analisou Andrade (2008), constituiu-se uma geografia ideográfica que limitava o papel da geografia na construção de um conhecimento mais geral.

\title{
Geografia Teorético-Quantitativa na Revista Brasileira de Geografia e no Boletim Geográfico
}

A Geografia Teorético-Quantitativa surgiu, segundo Andrade (2008, p. 172), na Suécia, Estados Unidos e Inglaterra, onde era essencialmente caracterizada por trabalhar em suas pesquisas com modelos estatísticos e matemáticos, como matrizes, a fim de alcançar resultados práticos. Ainda de acordo com o autor, no Brasil ela começou a inserir-se em fins da década de 1960 e década de 1970, amplamente incentivada pelo governo ditatorial militar que tinha o intuito de transpor a economia brasileira a condição de dependente da economia global. No 
entanto, vale destacar que esta política macroeconômica teve sérios impactos na economia brasileira, nos anos subsequentes ao período ditatorial, como o aumento exorbitante da dívida externa do Brasil.

Segundo Bessa (2004), a Geografia Teorético-Quantitativa se constituiu baseada no positivismo lógico ou neopositivismo, em que além de introduzir no seio da Ciência Geográfica mudanças de cunho epistemológico, foi também responsável por mudanças no âmbito metodológico. Assim, transformando a natureza investigativa da Geografia, e, consequentemente, da Geografia Agrária.

No Boletim Geográfico, um dos primeiros artigos publicados que se insere nessa corrente de pensamento e forma de produzir geografia é o artigo "Plano de coleta para a pesquisa sobre o abastecimento da cidade de São Paulo em gêneros alimentícios" do autor Seabra (1969). Nesse artigo, as categorias de análise paisagem, região e espaço perdem terreno para as noções estatísticas e matemáticas que embasam a pesquisa para o alcance do objeto de estudo. Entre os principais modelos matemáticos e estatísticos utilizados estão: amostragem e medida-padrão.

Ademais, no Boletim Geográfico constam outros artigos que trabalham com técnicas estatísticas as questões agrárias, como Diniz (1970), onde o mesmo prioriza no artigo o uso de coeficientes matemáticos para o cálculo da eficiência da agricultura na depressão periférica paulista. Abaixo segue um trecho que evidencia bem essa metodologia de análise:

Fomos obrigados, portanto, a criar um novo índice, que pudesse exprimir não só a eficiência agrícola mas também a eficiência da pecuária, e que permitisse ainda a junção dos dois, caracterizando a eficiência da agropecuária. (DINIZ, 1970, p. 67)

Além disso, outro trabalho publicado no Boletim Geográfico de Steffan e Brito (1977) contém aspectos em sua construção teórica e metodológica que o ligam a Nova Geografia ou Geografia Teorético-Quantitativa, haja vista que na pesquisa efetuada, do mesmo modo que os demais artigos dessa escola, o artigo apresenta afinidade com técnicas estatísticas e matemáticas, como a análise fatorial, fato que evidencia a influência dos postulados do positivismo lógico na construção do trabalho.

Além disso, nos artigos da Revista Brasileira de Geografia ligados a essa corrente teórico-metodológica, destacam-se trabalhos relacionados à aplicação do modelo de Von Thünen nos estudos em Geografia Agrária, em que se enfatiza a descoberta dos anéis agrários em diversas áreas do Brasil. Entre esses estudos, podemos destacar o de Geiger; Lima; Abib (1974), que buscou aplicar a teoria do Estado Isolado de Von Thünen no Centro-Sul do Brasil, onde o principal mercado consumidor seria a cidade de São Paulo, assim passariam através de sua influência a serem construídos os anéis agrários em seu entorno. 
Não obstante, na Revista Brasileira de Geografia, também estão presentes outras publicações que tratam de questões agrárias através dessa perspectiva quantitativista, estas trabalham com índices e cálculos estatísticos para a determinação de regiões agrícolas, como fizeram Mesquita e Tietzman (1970), que através da utilização destas técnicas, foram estabelecidas as regiões agrícolas do Estado do Paraná.

\section{Geografia Crítica na Revista Brasileira de Geografia e no Boletim Geográfico}

A Geografia Crítica teve suas origens na Europa no pós-segunda guerra onde diversos teóricos europeus aprofundaram e aproximaram seus estudos do Marxismo. Nesse período, a Geografia Teorético-quantitativa começava a ser contestada por estar a serviço do capital e pouco preocupada com as injustiças sociais que passam a ser enfocadas pela Geografia Crítica (MOURA et al, 2008).

No Brasil, os primeiros estudos relacionados à Geografia Crítica remetem à década de 1970, como relata Andrade (2008):

As idéias radicais ou críticas, tanto oriundas dos Estados Unidos como da França,
repercutiram no Brasil, nos fins da década de 70 . Houve, assim, uma confluência de
fontes diferentes alimentando a produção geográfica brasileira [...] (ANDRADE, 2008,
p. 207)

Além disso, vale ressaltar que, nessa corrente do pensamento geográfico, apesar das diferentes abordagens segundo Moura et al (2008), o método empregado é o materialismo histórico ou também conhecido como dialética marxista que estrutura o conhecimento de modo a conceber as relações sociais contraditórias que constroem o espaço geográfico.

No Brasil, um dos pensadores da Geografia Agrária Crítica é Ariovaldo Umbelino de Oliveira, o qual através de sua tese de doutorado "Crítica ao estado isolado de Von Thünen: contribuição para o estudo da geografia agrária" (2016) rompe com os postulados quantitativistas através de uma crítica ao Estado Isolado de Von Thünen que repercutiu nos estudos desenvolvidos em Geografia Agrária até então.

Nesse contexto, alguns artigos do Boletim Geográfico e da Revista Brasileira de Geografia se encaixam nos postulados gerais da Geografia Crítica, demonstrando interesse pelas relações socioespaciais contraditórias existentes no campo brasileiro.

No Boletim Geográfico, não foi encontrado algum artigo propriamente da Geografia Crítica, não obstante foi identificado um artigo que se aproxima bastante dos postulados dessa corrente de pensamento. Guimarães (1962) tece críticas ao sistema latifundiário, à concentração de terras, às injustiças sociais além de defender a lei que delineia a função social das terras. No artigo, o autor trabalha com termos como descapitalização, regime de propriedade de terras, 
regime de trabalho, entre outros que trabalham a questão das relações capitalistas no campo, mas sempre através de uma perspectiva crítica.

Na Revista Brasileira de Geografia, foram identificados dois artigos com vinculação teórica, metodológica e conceitual com a Geografia Crítica, datando das décadas de 1980 e 1990. Nos anos 1990, a Geografia Agrária Crítica ganhou força, continuando a apresentar artigos na RBG, como o "Camponeses do Paraopeba: diagnóstico e alternativas" de Gerardi et al (1990). Neste artigo, predomina a abordagem marxista nos estudos das atividades agrícolas, dando-se ênfase a questões como acesso a terra, mão de obra e relações sociais de produção, temáticas que são recorrentemente trabalhados em textos da Geografia Agrária Crítica.

Além disso, Santos et al (1987), desenvolve a perspectiva da Geografia Crítica ao trabalhar as relações sociais de produção no campo brasileiro, destacando temáticas como concentração fundiária, proletarização e defesa da Reforma Agrária. Além disso, os autores mantem rigor teórico em suas considerações, onde termos antes utilizados indiscriminadamente como o de estrutura agrária, são devidamente conceituados, como evidencia o trecho abaixo:

\footnotetext{
A estrutura agrária engloba o processo de acesso à propriedade da terra, incluindo o sistema de exploração da mesma, a maneira como as culturas se distribuem na superfície terrestre, bem como as relações existentes entre proprietários e trabalhadores agrícolas, inclusive os sem terra. (SANTOS; ANDRADE; OLIVEIRA, 1987, p. 121)
}

Nesse sentido, alguns conceitos são analisados majoritariamente nos trabalhos da Geografia Crítica, como a questão da estrutura fundiária, a proletarização do campesinato, a concentração fundiária e a reforma agrária. Ademais, são textos que mantêm uma visão críticoanalítica dos problemas agrários tratados, ou seja, é uma geografia que está preocupada com a realidade e não apenas em estudá-la.

\section{Categorias, escalas de análise e temáticas recorrentes em publicações da Revista Brasileira}

\section{de Geografia e do Boletim Geográfico}

No âmbito dos resultados da pesquisa, as análises dos dados obtidos evidenciaram importantes tendências teóricas nos dois periódicos que puderam ser verificadas através da análise dos artigos publicados, tanto na RBG quanto no Boletim Geográfico. Ademais, entre outros resultados que serão pormenorizadamente elucidados, destaca-se a relação entre as temáticas presentes nos artigos e o contexto político-cultural dos períodos em que os mesmos foram publicados, fato que nos indicou que a produção do conhecimento em Geografia Agrária nos periódicos esteve, muitas vezes, ligada a interesses estatais com finalidades que variaram no tempo e no espaço. 
Na conjuntura dos resultados do Boletim Geográfico e RBG, inicialmente pesquisamos as categorias geográficas de análise que estiveram presentes nos artigos publicados nos periódicos para compreendermos quais tendências teóricas sobressaíram nos referenciais teórico-metodológicos das produções textuais analisadas. Nesse contexto, os dados obtidos foram agrupados no gráfico 01 , que sintetiza as principais categorias utilizadas nos artigos:

Figura 1 - Categorias presentes em pesquisas da RBG e do Boletim Geográfico

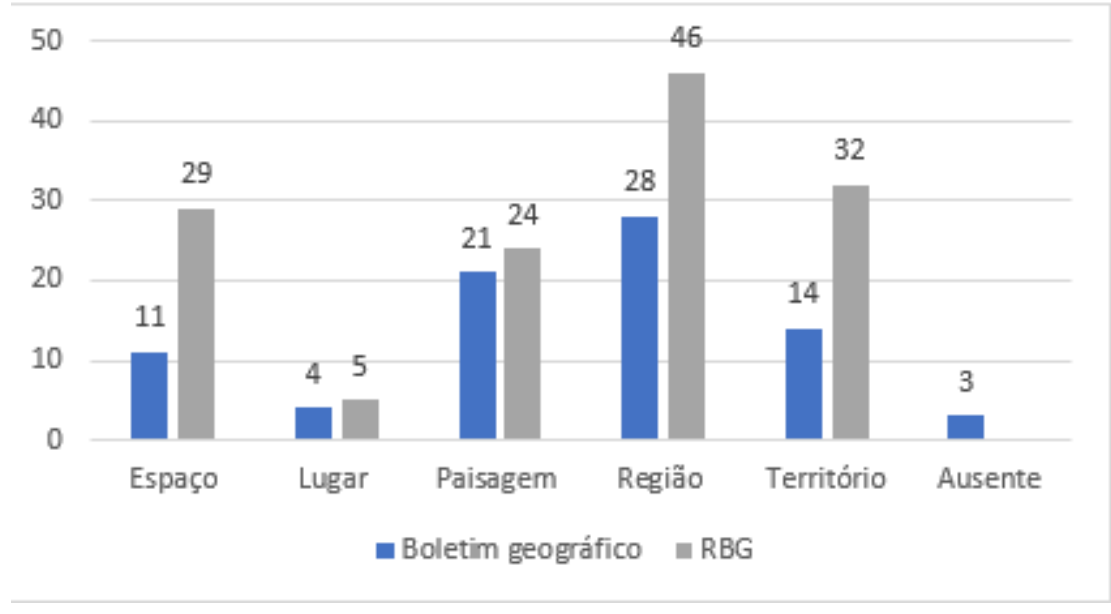

Elaboração: Autores

No caso do Boletim Geográfico, a categoria mais utilizada nos artigos analisados foi a de Região, aparecendo em 28 das 36 publicações pesquisadas. Essa categoria, muito vinculada aos estudos da Escola Francesa, esteve presente nos primeiros artigos desse periódico, entre os quais, podemos destacar as produções dos autores Monbeig (1953) e Deffontaines (1953) que na discussão das temáticas agrárias incluíram a categoria região nos seus estudos sobre agricultura, estrutura agrária e pecuária. Ademais, vale salientar que essa categoria, nos artigos analisados do Boletim Geográfico, esteve presente em muitos artigos junto a outra categoria que teve grande representatividade no conjunto da revisão bibliográfica enfocada: a paisagem.

Essa tendência foi verificada em boa parte das publicações pesquisadas, em que, do conjunto total de artigos analisados, 21 publicações apresentaram a discussão de suas temáticas englobando as duas categorias de análise, ora exclusivamente, ora utilizando também outras categorias que tiveram menor representatividade quantitativa na revista, como território e espaço.

Nesse contexto, apesar das categorias região e paisagem predominarem no conjunto da revisão efetuada no Boletim Geográfico, a categoria território esteve presente em 14 artigos analisados, nos quais ela é majoritariamente vinculada ao conceito de território como Estadonação. Assim, o território enfocado nesses artigos é principalmente o "território nacional”, ou 
seja, ele refere-se a territórios delimitados oficialmente como é o caso do próprio território brasileiro e não às múltiplas concepções atuais que veiculam no interior da Ciência Geográfica.

Ainda nesta temática, os dados obtidos da RBG ilustram diferenças pontuais que revelam alguns aspectos que diferenciam os dois periódicos no que tange os seus aspectos teóricos.

Em primeiro lugar, os dados do gráfico reforçam uma tendência que foi verificada nos artigos do Boletim Geográfico, o predomínio da categoria região nas publicações analisadas, das 47 pesquisadas na RBG, 46 continham a categoria região utilizada no desenvolvimento das temáticas. Assim, em ambos os periódicos essa categoria predominou, o que por consequência influenciou as escalas de análise das pesquisas, como posteriormente apontaremos.

Em seguida, a análise dos dados indicou uma mudança da RBG frente aos resultados do Boletim Geográfico, haja vista que as categorias território e espaço ganham terreno no âmbito das publicações analisadas, diferenciando-se do Boletim Geográfico, em que prevaleceu em segundo lugar a categoria paisagem.

Na RBG, a categoria território esteve presente em 32 artigos dos 47 enfocados e, assim como no Boletim Geográfico, ela esteve preponderantemente ligada à noção de território nacional. Não obstante, foi verificado em um artigo da Geografia Crítica que a categoria território foi desvinculada dessa noção, nela os autores passam a conceber o território como um ente historicamente produzido e não apenas uma área de controle legalmente instituída.

Por fim, além de território, a categoria espaço também se apresentou em números expressivos estando presente em 29 artigos da RBG o que indica um contraponto aos resultados do Boletim Geográfico em que essa categoria teve pouca expressão no periódico. Na RBG, essa categoria apresenta-se nos artigos junto a outras, como território, região e paisagem e apenas no artigo de Marques (1971) ela é utilizada em separado das demais no estudo da estrutura agrária do estado de Pernambuco.

Ademais, a categoria que teve menor representatividade em ambos os periódicos foi lugar, a qual figurou em última posição no quantitativo dos artigos analisados nos dois periódicos. Assim, verificou-se a predominância das categorias região, território, paisagem e espaço nas publicações analisadas de ambos os periódicos, valendo ressaltar que, em cada um deles, as categorias citadas variam quando consideramos a análise dos periódicos separadamente. Nesse contexto, a utilização dessas categorias influenciou, como já citado, a delimitação das escalas de análise das pesquisas efetuadas no Boletim Geográfico e na RBG. Abaixo, segue o gráfico 02 que indica as principais escalas de abordagem utilizadas nos artigos do Boletim Geográfico e na RBG: 
Figura 2 - Escalas de análise

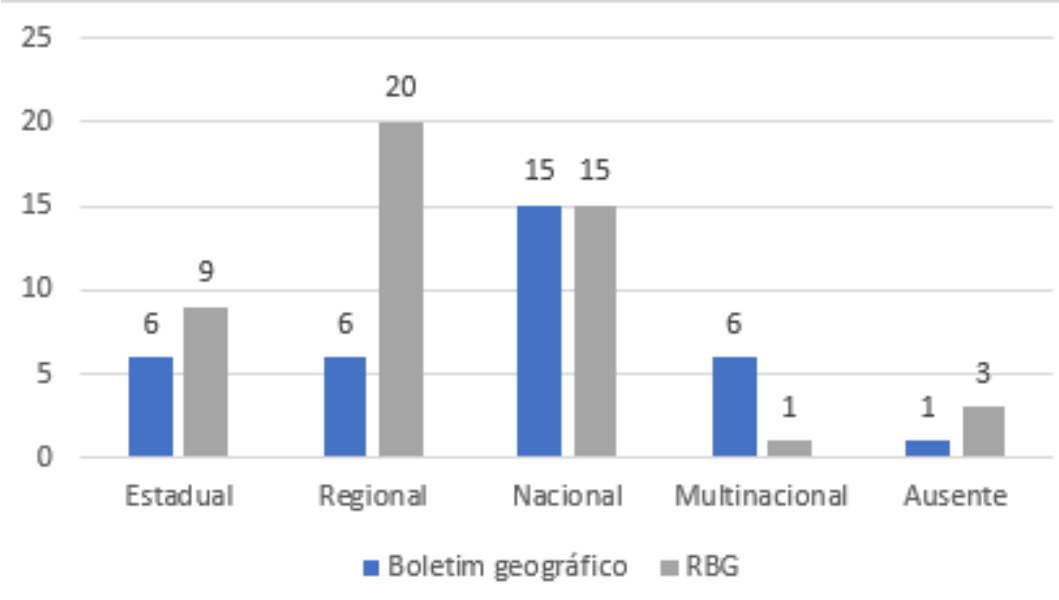

Elaboração: Autores

$\mathrm{Na}$ análise dos dados do Boletim Geográfico, é perceptível a prevalência da escala de análise nacional (44\%), seguida pela estadual e regional (18\%) e, por fim, marcaram presença a escala multinacional (17\%) e artigos que não possuem escalas de análise propriamente ditas (3\%). Nos estudos com a escala nacional de análise, os pesquisadores discutiram temas diversos da Geografia agrária, como a Reforma Agrária que foi discutida em alguns artigos do periódico nessa escala, entre esses estudos destacam-se Smith (1957) e Rios (1954).

No âmbito da escala regional, destacam-se como exemplos artigos ligados a diferentes correntes do pensamento geográfico como a pesquisa de Orlando Valverde (1961), autor considerado precursor do pensamento crítico em Geografia Agrária, e a de Diniz (1970) ligado à Geografia teorético-quantitativa. Ainda nesta temática, é imprescindível detalhar a localização dessas regiões para que se possa compreender que áreas do espaço agrário brasileiro foram investigadas pelas publicações do periódico, assim ao investigar essa questão, constatamos que as regiões estudadas estavam localizadas, majoritariamente, nas Regiões Nordeste e Sudeste.

Ademais, a escala estadual que obteve percentagem igual a escala regional também esteve presente desde os primeiros artigos publicados no Boletim Geográfico, ligados à Geografia Clássica, até os mais recentes vinculados a Teorético-quantitativa. No âmbito dos estados que mais foram estudados nos artigos, destacou-se São Paulo sendo estudado em três artigos, já a Paraíba e Pernambuco também foram analisados, mas apenas em uma publicação. Outros estados não estiveram presentes em estudos utilizando escala estadual de análise na revisão bibliográfica efetuada.

Além dos dados obtidos no periódico supracitado, o estudo das escalas de análise também englobou a RBG, na qual verificou-se que a escala de análise predominante foi a regional (42\%), em seguida veio a nacional (31\%), estadual (19\%), ausente $(6 \%)$ e 
multinacional (2\%). Esses resultados ilustraram diferenças marcantes quando comparadas com os dados obtidos na análise da mesma variável no Boletim Geográfico.

Inicialmente, é essencial destacar que uma das mudanças na tendência verificada na RBG quando contrastada com o Boletim Geográfico é a preponderância da escala regional de análise que esteve presente em quase metade de todos os artigos analisados. Esse fato reforça a influência da categoria região na produção desse periódico, influência esta que foi notada pela presença quase integral nos artigos de geografia agrária analisados na RBG. Partindo dessa conjuntura, é perceptível que a utilização da categoria região no decorrer dos artigos analisados influenciou a delimitação da escala de análise dos mesmos, como ocorreu no artigo de Valverde (1948) “Excursão à Região Colonial Antiga do Rio Grande do Sul” em que a categoria região é utilizada tanto como instrumento de análise como também acaba por determinar a escala de abordagem do estudo, o qual constitui uma monografia regional.

Ainda nesse contexto, vale destacar em quais grandes regiões as áreas estudadas nesses periódicos pertencem, desse modo, foi verificado que a maioria dos artigos está vinculada à discussão de temáticas referentes ao espaço agrícola do Centro-Sul (Sul, Sudeste e CentroOeste) e do Nordeste. A região Norte possui pouca participação no conjunto de artigos analisados, revelando uma carência de estudos sobre essa região no periódico. Ademais, caso seja considerado a análise individual das grandes regiões, o Nordeste assume o lugar de região com maior representatividade de estudos nas análises regionais de artigos da RBG.

Além disso, a escala nacional de análise das temáticas agrárias figurou junto à regional como majoritárias, ficando em segundo lugar (31\%) no número de artigos em que a mesma foi enfocada. Nesse contexto, as produções analisadas que utilizaram esta escala enfocaram diferentes temáticas, como a Reforma Agrária, culturas agrícolas, organização espacial e regionalização agrícola do país, portanto, não apresentaram apenas uma tendência de estudo específica, mas, nessa escala, englobaram diferentes temáticas referentes aos aspectos agrários brasileiros.

Por fim, a análise denotou que outras escalas também estiveram presentes nos artigos pesquisados, entre as quais destacou-se a escala estadual de análise que manteve um índice de utilização nos artigos da RBG (19\%) similar aos resultados do Boletim Geográfico (18\%). Nesse âmbito, os estados que mais apareceram como objeto de análise nos estudos foram os estados do Paraná, Minas Gerais e Rio Grande do Sul. Além destes, outros foram estudados pontualmente, como Roraima e Bahia, mas a tendência verificada foi que a maioria dos estados estudados por meio dessa escala eram do Centro-Sul brasileiro, os estados do Nordeste e Norte 
tiveram contraditoriamente pouca representatividade nos estudos que focalizaram escalas estaduais.

Ademais, perscrutamos nos dois periódicos quais os temas principais observados nas correntes teóricas presentes nos mesmos, a fim de podermos compreender quais temáticas eram estudadas com mais afinco por cada uma das escolas do pensamento geográfico que tem artigos representando-as em ambos os periódicos. Abaixo segue diagrama $01^{3}$ que ilustra as principais temáticas observadas no Boletim Geográfico:

Figura 3 - Principais temáticas verificadas em publicações do Boletim Geográfico

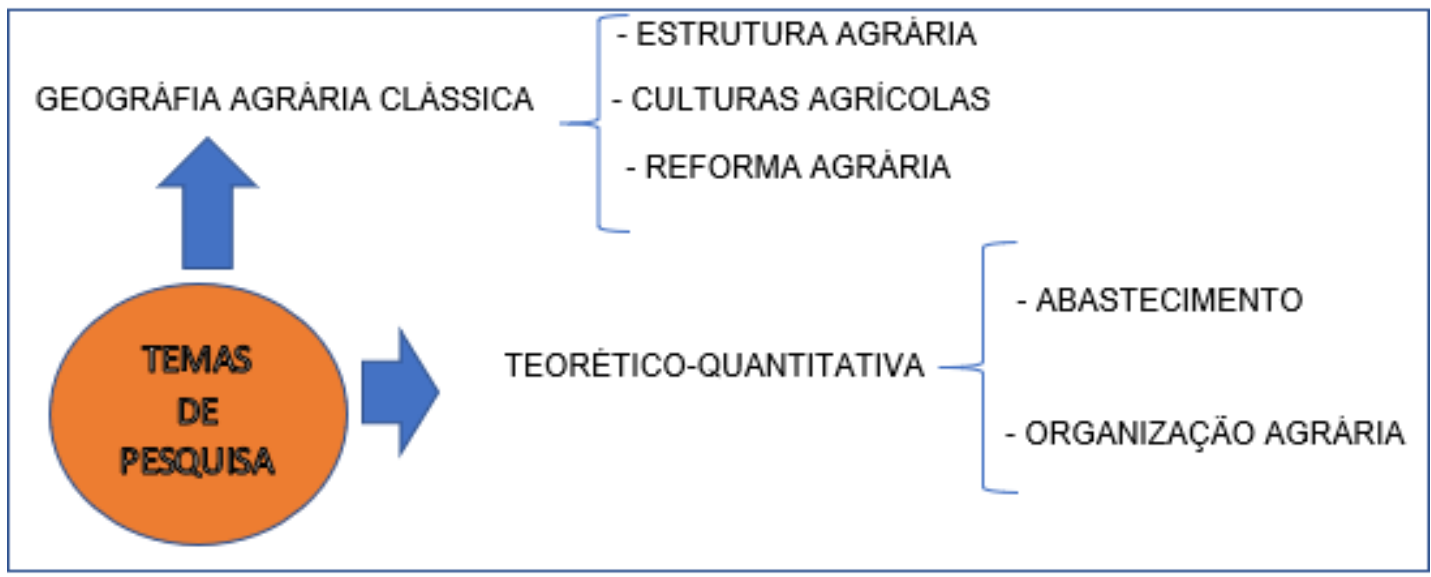

Elaboração: Autores

Assim, no Boletim Geográfico diferentes temas preponderaram em decorrência do período em que os artigos foram publicados e das correntes de pensamento em que estiveram inseridos. Como o diagrama indica, na Geografia Agrária Clássica, os temas predominantes foram pesquisas sobre culturas agrícolas, com destaque para a cana-de-açúcar, a qual esteve presente nos primeiros artigos publicados em Geografia Agrária no Boletim Geográfico. Além da cana-de-açúcar, outros estudos se dedicaram a outras culturas, como a fumicultura estudada por Andrade (1963), e a cafeicultura abordada por Soares (1951).

Além dos estudos referentes às culturas agrícolas, outras duas temáticas que despontaram como influentes nos artigos analisados foram a estrutura fundiária e a Reforma Agrária que são temáticas intrinsecamente vinculadas, tendo em vista que a estrutura fundiária brasileira foi e ainda é marcada pela extrema concentração de terras. Nesta conjuntura, o debate pela tão necessária reforma agrária como medida de promoção da justiça social se fez presente tanto no campo científico, quanto no político.

\footnotetext{
${ }^{3}$ A geografia agrária crítica não foi incluída na análise em decorrência de haver apenas um artigo no periódico.
} 
Um dos textos que materializa esse pensamento foi o produzido pelo sociólogo americano Lynn Smith em seu artigo “Alguns princípios fundamentais da Reforma Agrária” de 1957, onde após trabalhar como consultor junto ao ministro da agricultura em 1952, produz em 1957 o artigo supracitado em que o autor aponta as melhorias que a Reforma Agrária traria tanto para a terra quanto para os camponeses. Além disso, outros autores debruçaram-se sobre esta temática de pesquisa, apontando as necessidades da realização e os rumos que ela deveria tomar, como o fez Rio (1954).

Contrapondo-se com essas temáticas, os artigos vinculados à Geografia TeoréticoQuantitativa, publicados em fins da década de 1960 e década de 1970, destacam como principais temáticas o abastecimento agrícola e a organização agrária, temáticas como a Reforma agrária passam a não ser priorizados, haja vista que o direcionamento governamental da ditadura militar volta-se contra essa política pública. Nesse contexto, ganham importância as técnicas estatísticas na análise das questões em Geografia Agrária, como a análise fatorial, formulação de índices, entre outros.

Nesta perspectiva, também examinamos as principais temáticas discutidas nos artigos da $\mathrm{RBG}$, os resultados desta pesquisa seguem na figura abaixo:

Figura 4 - Principais temáticas verificadas em publicações da RBG

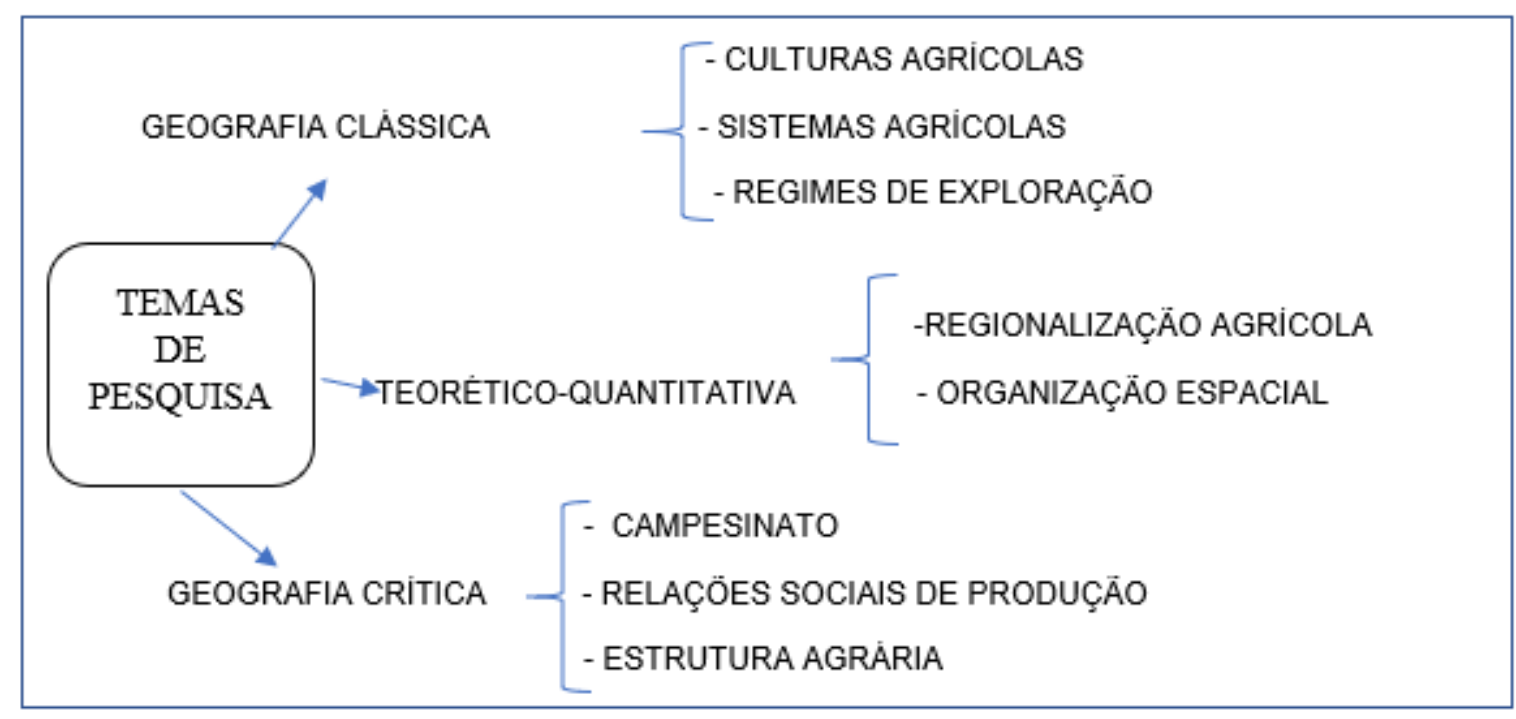

Elaboração: Autores

$\mathrm{Na}$ análise dos resultados do diagrama, os quais englobam os principais temas discutidos nos artigos da RBG, é possível constatar que em linhas gerais alguns temas discutidos no Boletim Geográfico são também tratados nas publicações da RBG, como o estudo das culturas agrícolas. Além disso, na Geografia Clássica foram estudadas outras temáticas, como sistemas agrícolas e regimes de exploração, nessa perspectiva vale destacar que essas temáticas, muitas 
vezes, não eram discutidas isoladamente, mas junto a outras dimensões que compunham as características das atividades agrárias desenvolvidas nos locais analisados, como o fez Valverde (1961) no estudo da geografia agrária do Baixo Açu.

Além disso, na Geografia Teorético-Quantitativa, as temáticas predominantes foram as regionalizações agrícolas aplicadas a estados e áreas de diferentes escalas, além dos estudos referentes à organização espacial. Contrastando com essas temáticas, os artigos da Geografia Crítica destacaram em suas pesquisas discussões sobre as relações sociais de produção, a estrutura agrária dos locais estudados e o campesinato. Além disso, assumem a defesa da Reforma agrária, apontando justificativas e sua real necessidade frente a estrutura agrária concentrada dos locais abordados.

Por fim, pesquisamos, em ambos os periódicos, os gêneros alimentícios abordados nos artigos, para assim compreendermos quais deles eram destacados nos estudos de Geografia Agrária e em que perspectivas eles eram estudados, individualmente ou de forma conjunta. Diante disso, abaixo seguem os resultados em tabela dos artigos do Boletim Geográfico e da RBG.

Tabela 1 - Principais gêneros alimentícios presentes em estudos no Boletim geográfico e na RBG.

\begin{tabular}{|c|c|c|}
\hline GÊNEROS ALIMENTíCIOS & $\begin{array}{c}\mathbf{N}^{\circ} \text { de artigos em que estão } \\
\text { presentes no Boletim Geográfico }\end{array}$ & $\begin{array}{c}\mathbf{N}^{\circ} \text { de artigos em que estão } \\
\text { presentes na RBG }\end{array}$ \\
\hline Algodão & 9 & 15 \\
\hline Arroz & 11 & 23 \\
\hline Batata-doce & 4 & - \\
\hline Batatas & - & 11 \\
\hline Beterraba & 3 & 5 \\
\hline Cacau & 3 & 22 \\
\hline Café & 10 & 20 \\
\hline Cana-de-açucar & 15 & - \\
\hline Cevada & 2 & 26 \\
\hline Feijão & 7 & 11 \\
\hline Fumo & 6 & 21 \\
\hline Mandioca & 10 & 31 \\
\hline Milho & 11 & 11 \\
\hline Soja & - & 14 \\
\hline Trigo & 5 & \\
\hline
\end{tabular}

Elaboração: Autores

Nesse contexto, predominaram os estudos acerca da monocultura canavieira no periódico, sendo a sua importância retratada em seus aspectos econômicos, sociais e culturais. $\mathrm{Na}$ maioria dos artigos, a área destacada nos estudos é a zona da mata nordestina, que teve durante séculos a cultura canavieira como principal atividade agrícola regional. Ademais, é importante delinear que as publicações, em alguns casos, dedicavam-se ao estudo exclusivo dessa cultura, como fizeram Melo (1948), Freire (1951) e Carli (1948). 
Em posições diametralmente opostas da cana-de-açúcar, situam-se o milho e a mandioca que junto a outros gêneros alimentícios não possuem artigos no Boletim Geográfico que os estudem individualmente. Esses gêneros alimentícios são, nos artigos pesquisados, vinculados majoritariamente a culturas alimentares e não monoculturas com as características socioeconômicas da cana-de-açúcar. As mesmas são produzidas principalmente por camponeses para o efetivo sustento alimentar, a mandioca, inclusive, considerada a "lavoura do pobre" era plantada em posição secundária a da cana-de-açúcar para a alimentação das classes menos abastadas.

Por fim, outra cultura que teve representatividade no Boletim Geográfico foi a cafeicultura, estando presente em 10 artigos analisados. Os estudos publicados que abordavam essa cultura situam-se principalmente no Sudeste, em especial no estado de São Paulo, onde essa cultura teve grande importância econômica e social. Neste cenário, um dos estudos que ilustra sinteticamente esse fato é o artigo "As estruturas agrárias das faixas pioneiras paulistas" de Monbeig (1953), o qual retrata além da estrutura fundiária paulista o papel do café nesse processo.

No âmbito da RBG, os resultados apresentam divergências pontuais. Nessa conjuntura, verifica-se que o produto de maior representatividade nos artigos foi o milho, com 31 artigos que citam esta cultura, mas valendo destacar que na maioria dos casos essa cultura está vinculada a pequenos produtores, não sendo cultivada no sistema monocultor. Ademais, essa cultura é frequentemente estudada junto a outras, como ocorreu no Boletim Geográfico. Um dessas culturas é a do feijão que apresenta- se em 26 artigos analisados, no entanto é analisada junto a tantas outras, como ocorre com o milho.

Além disso, a cultura cafeeira é citada em 22 artigos na RBG, assumindo em alguns deles papel central nas pesquisas desenvolvidas, em que são destacados seus aspectos históricos, econômicos e sociais, como o fez Valverde (1967) ao analisar a cafeicultura brasileira principalmente no período escravocrata. Outra monocultura abordada nos artigos foi a canavieira que, entretanto, não estava presente na maioria dos artigos como no Boletim Geográfico. A mesma continua a ser estudada, em alguns casos individualmente, mas é notável que a importância que ela desempenhou nas temáticas de pesquisas do Boletim Geográfico diminuiu quando comparada aos resultados da Revista Brasileira de Geografia.

Por fim, outros produtos aparecem em muitos artigos, como o Arroz (23), Algodão (15), Trigo (14) os quais em alguns casos são estudados ora isoladamente, como o trigo e o arroz foram em alguns artigos, ora junto a outras culturas agrícolas ligadas a pequena produção. A 
rizicultura do Sul do Brasil, por exemplo, foi estudada tanto detalhadamente por Bernardes (1954) quanto enquadrada junto a outras culturas agrícolas, como o fez Magnano (1995).

\section{CONSIDERAÇÕES FINAIS}

O estudo da historiografia da Geografia Agrária brasileira revelou-a como uma área dinâmica na produção do conhecimento em Geografia, haja vista que inúmeros artigos foram publicados com temáticas referentes ao mundo agrário brasileiro no decorrer do século XX. Nesse período, muitos aspectos da realidade agrária brasileira foram elucidados por diferentes autores, com diferentes métodos científicos, teorias e paradigmas que guiaram seus estudos acerca de muitas problemáticas que surgiam nos contextos históricos específicos em que os autores os refletiram.

Em síntese, através do desenvolvimento da pesquisa, pudemos compreender os principais elementos teórico-metodológicos presentes nos artigos selecionados no Boletim Geográfico e na RBG. Assim, contribuindo para entendermos a história da Geografia Agrária nos dois periódicos que ao longo da revisão efetuada apresentou-se, em diferentes momentos, com particularidades marcantes, sendo influenciada por fatores políticos, teóricos e sociais da realidade brasileira.

Finalmente, constatamos que a região foi a categoria geográfica prevalente nos estudos agrários analisados, tanto na RBG, como no Boletim Geográfico, discutida principalmente sob a ótica historicista ou positivista. Além disso, a descrição presente na Geografia Agrária Clássica foi gradualmente substituída pela análise estatística da Geografia Teórica-Quantitativa. As preocupações sociais, que floresceram no Brasil com a ascensão da Geografia Crítica, foram praticamente inexpressivas nos artigos analisados na RBG e no Boletim Geográfico.

\section{REFERENCIAS}

ANDRADE, M. Côrrea. Geografia ciência da sociedade. Recife: Ed. Universitária da UFPE, 2008, $246 \mathrm{p}$.

ANDRADE, M. Considerações geo-econômicas sôbre a cultura do fumo no Brasil. Boletim Geográfico: Rio de Janeiro, v. 21, n. 173, p. 181-184, mar./abr. 1963.

BERNARDES, Nilo. O problema do estudo do habitat rural no Brasil. Boletim Geográfico: Rio de Janeiro, v. 22, nº 176, p. 529-544, set./out. 1963.

BERNARDES, L. M. Cavalcanti. Cultura e produção do arroz no Sul do Brasil. Revista Brasileira de Geografia: Rio de Janeiro, v.16, n. 4, p. 403-438, out./dez. 1954.

BESSA, Kelly Cristine. A Diferenciação Espacial e as Interpretações da Geografia TeoréticoQuantitativa e da Geografia Crítica. Sociedade e Natureza, Uberlândia, v. 16, n. 31, p. 101124, dez, 2004. 
CARLI, Gileno de. Geografia Economica e Social da cana-de-açúcar no Brasil. Boletim Geográfico: Rio de Janeiro, v.6, nº 61, p. 8-33, abril, 1948.

CASTRO, Josué de. Áreas alimentares do Brasil. Boletim Geográfico: Rio de Janeiro, v.6, $\mathrm{n}^{\circ}$ 65, p. 456-466, agosto, 1948.

CREMER, H. D. Novas fontes de nutrição para combater o problema mundial de alimentação. Revista Brasileira de Geografia: Rio de Janeiro, v. 41,n³, p. 151-163, jul./set. 1979.

DEFFONTAINES, Pierre. História do Gado nos países do Prata particularmente no Uruguai. Boletim Geográfico: Rio de Janeiro, v. 11, nº 114, p. 249-257, mai./jun. 1953.

DINIZ, J. A. Felizola. Cálculo de eficiência da agricultura na depressão periférica paulista. Boletim Geográfico: Rio de Janeiro, v. 29, nº 218, p. 66-75, abril, 1970.

DUMONT, Renné. Produção alimentar e países subdesenvolvidos. Boletim Geográfico: Rio de Janeiro, v. 20, nº 166, p. 71-75, jan./fev, 1962.

FREIRE, Gilberto. A cana e a mata. Boletim Geográfico: Rio de Janeiro, v. 9, n. 104, p. 771 776, nov. 1951.

GEIGER, P. Pinchas; LIMA, M. S. N de Motta; ABIB, M. E. Abi. Distribuição de atividades agropastoris em torno da metrópole de São Paulo. Revista Brasileira de Geografia: Rio de Janeiro, v. 36, nº , p. 3 -36, out./dez. 1974.

GIRARDI, L. H. de Oliveira et al. Camponeses do Paraopeba: diagnósticos e alternativas. Boletim Geográfico: Rio de Janeiro, v. 52, n.2, p.75-82, abr./jun. 1990.

GUIMARÃES, A. Passos. A questão agrária brasileira. Boletim Geográfico: Rio de Janeiro, v. 20, nº166, p. 53-57, jan./fev. 1962.

MAGNANO, A. Alves. A modernização da agricultura no entorno do Distrito Federal e a questão ambiental. Revista Brasileira de Geografia: Rio de Janeiro, v. 57, n. 4, p. 35-46, out./dez. 1995.

MARQUES, J. Soares. Estrutura agrária do estado de Pernambuco. Revista Brasileira de Geografia: Rio de Janeiro, v. 33, n.2, p.137-148, 1971.

MELO, M. L. de. O fator geográfico na economia açucareira. Boletim Geográfico: Rio de Janeiro, v. 6, nº67, out. 1948.

MESQUITA, O. Vianna. O método de Von Thünem: uma discussão. Revista Brasileira de Geografia: Rio de Janeiro, v. 40, nº 2, p. 60-130, abr.jun. 1978.

MESQUITA, O. V.; TIETZMAN, Solange. Regiões agrícolas do Estado do Paraná: uma definição estatística. Revista Brasileira de Geografia: Rio de Janeiro, v.32, nº 1, p. 3-42, 1970.

MONBEIG, Pierre. As estruturas agrárias das faixas pioneiras paulistas. Boletim Geográfico: Rio de Janeiro, v. 11, nº116, p. 455-465, set./out. 1953.

MOURA, Rosa; et al. Geografia Crítica: legado histórico ou abordagem recorrente. Universidad de Barcelona Vol. XIII, nº 786, jun. 2008.

OLIVEIRA, A. Umbelino. Crítica ao estado isolado de Von Thünen: contribuição para o estudo da Geografia Agrária. São Paulo: Iandé Editorial, 2016, 530 p.

RIOS, J. Artur. Rumos da Reforma Agrária. Boletim Geográfico: Rio de Janeiro, v.12, n. 121, p. 169-176, jul./ago. 1954.

SANTOS, A. Figueiredo; et al. Homem, terra e trabalho no sertão sergipano do São Francisco.

Revista Brasileira de Geografia: Rio de Janeiro, v.49, n³, p. 117-138, jul./set. 1987. 
SEABRA, Manuel. Considerações geo-econômicas sobre a cultura do fumo no Brasil. Boletim Geográfico: Rio de Janeiro, v. 28, nº 209, p. 65-78, mar./abri. 1963.

SILVA, M. de C. dos Santos; NUNES, E. Duarte. Josué de Castro e o pensamento social brasileiro. Ciênc. saúde coletiva vol.22 no.11 Rio de Janeiro Nov. 2017.

SMITH, T. Lynn. Alguns princípios fundamentais da Reforma Agrária. Boletim Geográfico: Rio de Janeiro, v.15, n. 139, p. 476-483, jul./ago. 1957. Abr./jun.1947.

Sistemas agrícolas. Boletim Geográfico: Rio de Janeiro, v. 5, nº57, p. 984- 1003,

SOARES, S. Ferreira. Notas estatísticas sôbre a produção agrícola e carestia dos gêneros alimentícios no Império do Brasil. Boletim Geográfico: Rio de Janeiro, v. 9, n. 105, p. $927-$ 939, dez. 1951.

STEFFAN, E. Roque; BRITO, M. Socorro. Aplicação para uma análise fatorial para estudo de organização agrária na Paraíba e em Pernambuco. Boletim Geográfico: Rio de Janeiro, v. 35, n. 254, p. $22-47$, jul./set. 1977.

VALVERDE, Orlando. A fazenda de café escravocrata no Brasil. Revista Brasileira de Geografia: Rio de Janeiro, v. 29, n. 1, p. 37-81. 1967.

. Excursão à Região colonial antiga do Rio Grande do Sul. Revista Brasileira de Geografia: Rio de Janeiro, v.10, n. 4, p. 477-534, out./dez. 1948.

. Geografia Agrária do Baixo Açu. Revista Brasileira de Geografia: Rio de Janeiro, v. 23, n.3, p. 455-494, jul./set. 1961.

WAIBEL, Leo. A teoria de Von Thünen sobre a distância do mercado relativamente a utilização da terra. Boletim Geográfico: V. 10, nº 1, p. 3-40, jan./mar. 1948. 